\title{
Comparação eletromiográfica do exercício abdominal dentro e fora da água
}

\author{
Evelyn S.M. Müller ${ }^{1,2}$ \\ Gabriela L. Black ${ }^{1}$ \\ Paulo P. Figueiredo ${ }^{1}$ \\ Luiz F.M. Kruel ${ }^{1}$ \\ Claudia Hanisch ${ }^{2}$ \\ Hans J. Appell ${ }^{2}$
}

\section{RESUMO}

Este trabalho verificou a atividade elétrica dos músculos oblíquo externo, reto femoral e das porções supra-umbilical e infraumbilical do reto abdominal, durante a execução do exercício abdominal "sit up" em terra e água, em velocidade padrão e máxima. A amostra foi composta por 20 mulheres com idade entre 21 e 29 anos. A atividade elétrica foi medida com eletrodos de superfície. Para a normalização da amplitude do sinal foi utilizado o valor do root mean square (RMS). Para a análise estatística utilizou-se o teste de normalidade de Shapiro-Wilk e a ANOVA a três fatores. Os resultados demonstraram que o exercício na velocidade máxima, realizado em terra e no meio líquido, apresentou uma atividade EMG maior que o exercício realizado na velocidade padrão, com exceção do reto femoral. Ao analisar a fase ascendente no exercício aquático na velocidade máxima, observa-se que o reto abdominal e o oblíquo externo demonstraram uma atividade EMG tão eficiente quanto o mesmo exercício em terra. Demostrando, com isso, que a instabilidade da posição horizontal e a resistência ao movimento compensam a diminuição do peso hidrostático. O mesmo comportamento não ocorre na velocidade padrão.

Palavras-chave: abdominal, eletromiografia, meio aquático, meio terrestre, velocidade.

\author{
${ }^{1}$ Universidade Federal do Rio Grande do Sul \\ Escola Superior de Educação Física \\ Porto Alegre, Brasil \\ ${ }_{2}$ Universidade Alemã de Desporto \\ Instituto de Fisiologia e Anatomia \\ Colónia, Alemanha
}

\begin{abstract}
Electromyografic comparison of abdominal exercises in and out of water.

The electric activity of the obliqus externus abdominis, rectus femoris and the upper and lower portions of the rectus abdominis muscles were monitored during the "sit up" exercise in two different conditions land and water. Twenty women aged 21-29 year were studied. The electric activity was measured with surface electrodes. The value root mean square (RMS) of the ascending phase of this exercise was used for the normalization of the signal amplitude that was collected during the other variations of speed and conditions. The exercise was performed in a standard rhythm and at maximum speed. For each muscle, ANOVA was used for the factors phase, speed, and condition. The Shapiro-Wilk test of normality was applied. When the exercise was performed at maximum speed, the observed EMG activity was stronger than at standard speed, both in water and on land. The EMG activity of the rectus femoris at maximum speed in water was lower than on land. When analyzing the ascending phase in water at maximum speed, the abdominal muscles showed as much as EMG on land. These results demonstrate that the instability of the horizontal position and the resistance against the movement compensate the reduction of the weight by the effect hydrostatic pressure when the exercise is executed at maximum speed. The same pattern did not occur at standard speed.
\end{abstract}

Key Words: abdominal muscles, electromyography, water, land, velocity. 


\section{INTRODUÇÃO}

Almejando melhor qualidade de vida, o homem busca no meio líquido um ambiente no qual possa desenvolver-se e aumentar suas opções de melhoria de aptidão física, através da prática de exercícios ativos. Diversos autores, ao investigarem as respostas do organismo humano aos programas de treinamento aquático, comprovaram uma melhora na capacidade cardiorrespiratória e de resistência muscular localizada $(21,28,31,32)$. A hidroginástica, em virtude da grande demanda, seja por atletas de rendimento, seja por idosos, obesos e gestantes, vem se tornando um importante foco de investigação. Wilder e Brennan (34) afirmam que a prática de exercícios no meio líquido tornou-se uma alternativa eficiente para minimizar o efeito da redução das capacidades motoras, ocasionada com o envelhecimento. Há também, na água, a utilização de equipamentos ou de artifícios que façam com que o trabalho muscular aumente. Em terra, a resistência é determinada, em geral, pela quantidade de "peso" levantado em relação à gravidade, enquanto que na água a resistência é determinada pela flutuabilidade e coeficiente de forma dos equipamentos, da área de superfície do equipamento e pela velocidade com que o movimento é executado. No meio líquido, forças hidrodinâmicas agem no sistema locomotor em diferentes condições de movimento. As aplicações básicas dos princípios biomecânicos na água constituem a base para os programas de reabilitação de indivíduos com desordens músculo-esqueléticas (29). Atualmente, o homem tende a utilizar cada vez menos sua musculatura. $\mathrm{O}$ tempo de lazer é pequeno e o estresse é grande. As pessoas carecem de cuidados, tanto preventivos, como reabilitativos, para que possam compensar as conseqüências da inatividade física. Um dos maiores problemas de saúde está relacionado com as dores na região lombar. As causas da dor lombar estão normalmente relacionadas com falta de atividade da musculatura abdominal, com o sedentarismo e com a falta de orientação e conscientização dos indivíduos ao levantarem cargas pesadas. Os músculos da parede abdominal têm como função principal proporcionar estabilidade à coluna vertebral (12).

Conforme Vaz et al. (33) o trabalho dos músculos abdominais é de fundamental importância para o ser humano, pois estes músculos tendem a reduzir a compressão nos discos intervertebrais e auxiliam na melhora da mecânica respiratória e nos movimentos da pelve, colaborando assim na diminuição das dores lombares. O músculo reto abdominal é o principal responsável pela flexão do tronco e os músculos oblíquos pela respiração, estabilidade, desequilíbrio lateral e rotação do tronco.

São diversos os exercícios abdominais realizados no meio terrestre, sendo sua eficiência comprovada através de estudos eletromiográficos. Apesar do grande número de indivíduos que praticam a hidroginástica e executam exercícios abdominais, são poucos os estudos sobre a análise eletromiográfica feitos no meio aquático $(5,7,26)$. Esta carência de estudos se justifica pela necessidade de tecnologia específica e dificuldades para a realização da coleta de dados no meio líquido. Porém, Figueiredo (7) elaborou uma metodologia para o isolamento de eletrodos, possibilitando a detectação do sinal eletromiográfico no meio líquido. A análise do sinal eletromiográfico no meio líquido foi eficiente, tornando possível conhecer melhor as reações da atividade muscular quando o exercício é realizado no meio líquido. Tratando-se de estudos referentes a este assunto, denota-se que diversos autores $(3,8,9,10,11,16$, $19,23,25,26,27)$ investigaram a atividade elétrica do músculo no meio líquido apresentando proposições e recomendando a continuidade de pesquisas que abordem esta temática.

Neste sentido, este trabalho procurou responder ao seguinte problema: Como se comporta a atividade elétrica dos músculos abdominais (supra, infra, oblíquo externo e reto femoral) durante a execução do exercício abdominal sit-up no meio líquido em velocidades diferentes?

\section{MATERIAL E MÉTODOS}

A amostra foi composta por 20 mulheres sem problemas físicos, adaptadas ao meio líquido, com idade entre 21 e 29 anos. Cada participante da pesquisa assinou um termo de consentimento informado, previamente aprovado pelo comitê de ética da universidade, no qual constavam informações pertinentes ao experimento. Para esta pesquisa, foram utilizados fichas de dados individuais, eletromiógrafo (marca Paromed Medizintechnik GMBH) de 8 canais, com energia fornecida por um sistema de baterias. O sistema de coleta de dados operou na freqüência de amostragem 
de $1000 \mathrm{~Hz}$. O cabo possui um pré-amplificador com ganho de 100 e foi reamplificado no data logger pelo fator 8, desta forma o ganho foi de 800 vezes; eletrodos de superfície $\mathrm{Ag} / \mathrm{AgCl}$ : pré-amplificados com configuração bipolar (Tyco Healthcare, Mini MediTrace 100) e os cabos foram fixos com fita (7). Para o isolamento dos eletrodos foi utilizado adesivo oclusivo transparente (TEGADERM- 3M), cola de silicone (Loctite Super Flex.). Foram feitas as filmagens dos exercícios através do sistema de vídeo $2 \mathrm{D}$ Peak Performance, versão 5.3, com uma freqüência de amostragem de $60 \mathrm{~Hz}$. Estas foram gravadas em um vídeo cassete super VHS para posterior análise. Para ressaltar os pontos anatômicos, foram utilizadas fitas reflexivas adesivas de $2 \mathrm{~cm}$ de diâmetro. Utilizou-se um sinal luminoso que indicava o início da coleta eletromiográfica, para que houvesse o alinhamento entre o sinal eletromiográfico e a cinemática. Para a determinação da freqüência de execução dos exercícios utilizou-se um metrônomo e para a sustentação e posicionamentos dos indivíduos na água o acquatubo (equipamento flutuante de $6,5 \mathrm{~cm}$ de diâmetro e $160 \mathrm{~cm}$ de comprimento). O sistema de isolamento dos componentes, a preparação da pele e a colocação dos eletrodos foram apresentados em estudo piloto por Figueiredo et al. (7).

A musculatura monitorada foi a porção inferior e superior do reto abdominal, o músculo oblíquo externo e o músculo reto femoral. Os eletrodos foram colocados no ventre muscular. O eletrodo terra foi colocado sobre a espinha ilíaca.

Os indivíduos realizaram dois exercícios, em terra e na água: o exercício analisado em terra foi executado em decúbito dorsal, quadris e joelhos fletidos com os pés apoiados no solo. $\mathrm{O}$ movimento consistiu em flexionar o tronco e o quadril até à posição sentada. O exercício em água iniciou em decúbito dorsal, com apoio do membro superior no acquatubo, que passa por baixo das axilas, apoiando os braços no equipamento, membros inferiores sem apoio. O movimento consistiu em flexionar o tronco, sem que os membros inferiores se movimentassem. Para orientar o ritmo do exercício utilizou-se um metrônomo a 60 batimentos por minuto, que foi denominada de velocidade padrão. Além desta, solicitou-se aos indivíduos que realizassem o mesmo movimento na máxima velocidade possível. Entre cada execução teve um intervalo de dois segundos.
O sinal captado foi gravado no computador e analisado no programa SAD 32. Foi utilizado filtro para o alinhamento da base do sinal utilizando a ferramenta de remove DC; com o objetivo de suprimir as oscilações de freqüência baixas e altas foi aplicado o filtro tipo passa-banda Butterworth de $5^{\text {a }}$ ordem, nas freqüências de 20 a $400 \mathrm{~Hz}$; para remover prováveis picos do sinal foi aplicada a ferramenta de remove picos automáticos com janela de 30 e meio tamanho de 2; visto que após esta filtragem persistia um ruído de baixa freqüência, aplicou-se um filtro passar alta, na freqüência de $5 \mathrm{~Hz}$ Hamming. Após a filtragem dos sinais, foram realizados os recortes das fases ascendente e descendente. Destes recortes, foi verificado o valor RMS de cada fase. Foram realizados dois procedimentos de normalização na amplitude. O primeiro procedimento teve por objetivo verificar se houve interferência da situação experimental na amplitude do sinal eletromiográfico. Assim, utilizou-se a contração voluntária máxima (CVM) para normalizar os dados do exercício realizado na terra, antes e depois do exercício no meio líquido. Após este procedimento realizou-se o segundo procedimento de normalização, tendo sido utilizado o valor da fase ascendente do exercício realizado em terra na velocidade padrão para normalizar os dados que entraram nesta lista. Os valores normalizados de cada sujeito foram transportados para uma planilha, na qual se calculou a média e o desvio padrão do valor RMS de cada fase dos exercícios. Assim, obteve-se a média e desvio padrão da amplitude de cada fase de cada exercício.

Inicialmente, os dados obtidos no exercício realizado em terra na velocidade padrão, antes e depois da coleta do exercício aquático, foram objeto de tratamento estatístico e normalizados pela CVM. Nesses valores, utilizou-se o teste t pareado em cada músculo. Assim, pode-se identificar se houve interferência da situação experimental na amplitude do sinal eletromiográfico. Para avaliar a possibilidade de utilização dos testes paramétricos, realizou-se o teste de normalidade de Shapiro-Wilk, que é indicado para amostras com menos de 50 indivíduos. Para a análise dos dados foi utilizado uma ANOVA para cada músculo estudado pelos fatores fase, velocidade e meio. O nível de significância utilizado foi $\mathrm{p}<0,05$. Todos os testes estatísticos foram aplicados no programa estatístico SPSS versão 11.0. 


\section{RESULTADOS}

Os resultados do teste-t pareado demonstraram não haver diferenças estatisticamente significativas entre o exercício realizado antes e após o exercício realizado depois da situação experimental. Assim, pode-se considerar que a situação experimental não modificou a intensidade do sinal eletromiográfico dos músculos analisados, seja por fadiga, seja pelo contato da água no eletrodo. O teste de Shapiro-Wilk demonstrou valores de $\mathrm{p}<$ 0,05 com excepção do músculo reto femoral.

Tabela 1: Média da atividade $\varepsilon M G(\bar{X})$, desvios padrão $(\sigma)$ e número de sujeitos $(N)$ dos músculos reto abdominal superior (supra) e inferior (infra], obliquo externo e reto femoral. Na água, fases e velocidades diferentes.

\begin{tabular}{|c|c|c|c|c|c|c|c|c|c|c|c|c|c|c|c|}
\hline \multirow[t]{2}{*}{ Meio } & \multirow[t]{2}{*}{ Fase } & \multirow[t]{2}{*}{ Vel } & \multicolumn{3}{|c|}{ Supra } & \multicolumn{3}{|c|}{ Infra } & \multicolumn{4}{|c|}{ Obliquo Externo } & \multicolumn{3}{|c|}{ Reto Femoral } \\
\hline & & & & $\mathrm{N} \overline{\mathrm{X}}$ & $\sigma$ & & $\bar{x}$ & $(\%)$ & $\sigma$ & $\mathrm{N}$ & $\overline{\mathrm{X}}_{(\%)}$ & $\sigma$ & $\mathrm{N}$ & $\overline{\mathrm{X}}_{(\%)}$ & $\sigma$ \\
\hline \multirow{9}{*}{ Água } & \multirow[t]{3}{*}{ Asc. } & Pad. & 15 & 69,09 & $\pm 29,01$ & 15 & 68,24 & $\pm 39,50$ & 13 & 3 & 68,66 & $\pm 26,37$ & 9 & 42,78 & $\pm 12,11$ \\
\hline & & Máx. & 12 & 135,51 & $\pm 39,76$ & 11 & 123,56 & $\pm 37,91$ & 7 & & 106,35 & $\pm 24,60$ & 9 & 108,26 & $\pm 49,80$ \\
\hline & & Total & 27 & 98,61 & $\pm 47,47$ & 26 & 91,64 & $\pm 47,17$ & 20 & 20 & 81,85 & 31,15 & 18 & 75,52 & $\pm 48,69$ \\
\hline & \multirow[t]{3}{*}{ Desc. } & Pad. & 15 & 32,86 & $\pm 15,06$ & 15 & 28,35 & $\pm 19,43$ & 13 & 3 & 26,29 & $\pm 11,86$ & 9 & 23,04 & $\pm 13,06$ \\
\hline & & Máx.. & 12 & 61,56 & $\pm 34,13$ & 11 & 53,84 & $\pm 31,10$ & 7 & & 44,10 & $\pm 8,44$ & 9 & 49,93 & $\pm 31,17$ \\
\hline & & Total & 27 & 45,61 & $\pm 28,74$ & 26 & 39,13 & $\pm 27,63$ & 20 & 20 & 32,52 & 13,68 & 18 & 36,48 & $\pm 27,00$ \\
\hline & \multirow[t]{4}{*}{ Total } & Pad & 30 & 50,97 & $\pm 29,24$ & 30 & 48,29 & $\pm 36,70$ & 26 & 6 & 47,47 & $\pm 29,46$ & 18 & 32,91 & $\pm 15,89$ \\
\hline & & Máx. & 24 & 98,53 & $\pm 52,34$ & 22 & 88,70 & $\pm 49,17$ & 14 & 4 & 75,22 & $\pm 36,82$ & 18 & 79,10 & $\pm 50,25$ \\
\hline & & Total & 54 & 72,11 & $\pm 47,18$ & 52 & 65,39 & $\pm 46,56$ & 40 & 10 & 57,19 & $\pm 34,47$ & 36 & 56,00 & $\pm 43,56$ \\
\hline \multirow{9}{*}{ Terra } & & Pad. & 13 & 101,52 & $\pm 8,65$ & 12 & 91,80 & $\pm 26,16$ & 10 & 0 & 97,04 & $\pm 9,03$ & 10 & 100,76 & $\pm 09,53$ \\
\hline & \multirow[t]{3}{*}{ Asc. } & Máx.. & 15 & 130,10 & $\pm 23,31$ & 14 & 112,03 & $\pm 18,68$ & 11 & 1 & 107,82 & $\pm 17,47$ & 11 & 163,63 & $\pm 31,58$ \\
\hline & & Total & 28 & 116,83 & $\pm 22,93$ & 26 & 102,70 & $\pm 24,25$ & 2. & 1 & 102,69 & $\pm 14,82$ & 21 & 133,69 & $\pm 39,68$ \\
\hline & & Pad. & 13 & 73,52 & $\pm 14,19$ & 12 & 76,77 & $\pm 13,57$ & 10 & 0 & 75,26 & $\pm 15,23$ & 9 & 63,47 & $\pm 13,51$ \\
\hline & \multirow[t]{3}{*}{ Desc. } & Máx.. & 15 & 74,50 & $\pm 17,02$ & 14 & 73,45 & $\pm 13,93$ & 11 & 1 & 67,25 & $\pm 20,10$ & 11 & 65,14 & $\pm 14,57$ \\
\hline & & Total & 28 & 74,04 & $\pm 15,49$ & 26 & 74,98 & $\pm 13,59$ & 2. & 1 & 71,06 & $\pm 17,97$ & 21 & 64,39 & $\pm 13,75$ \\
\hline & & Pad & 26 & 87,52 & $\pm 18,34$ & 24 & 84,29 & $\pm 21,78$ & 20 & 20 & 86,15 & $\pm 16,53$ & 19 & 83,10 & $\pm 22,18$ \\
\hline & \multirow[t]{2}{*}{ Total } & Máx. & 30 & 102,30 & $\pm 34,66$ & 28 & 92,74 & $\pm 25,44$ & 22 & 2 & 87,54 & $\pm 27,72$ & 11 & 114,39 & $\pm 14,57$ \\
\hline & & Total & 56 & 95,44 & $\pm 29,01$ & 52 & 88,84 & $\pm 23,97$ & 42 & 12 & 86,87 & $\pm 22,82$ & 41 & 99,89 & $\pm 45,90$ \\
\hline \multirow{9}{*}{ Total } & \multirow[t]{3}{*}{ Asc. } & Pad. & 28 & 84,14 & $\pm 27,22$ & 27 & 78,71 & $\pm 35,66$ & 23 & 3 & 81,00 & $\pm 24,89$ & 19 & 73,30 & $\pm 31,54$ \\
\hline & & Máx. & 27 & 132,50 & $\pm 31,13$ & 25 & 117,10 & $\pm 28,67$ & 18 & 8 & 107,25 & $\pm 19,84$ & 20 & 138,72 & $\pm 48,66$ \\
\hline & & Total & 55 & 107,88 & $\pm 37,84$ & 52 & 97,17 & $\pm 37,55$ & 41 & 1 & 92,52 & $\pm 26,11$ & 39 & 106,84 & $\pm 52,46$ \\
\hline & \multirow[t]{3}{*}{ Desc. } & Pad. & 28 & 51,74 & $\pm 25,17$ & 27 & 49,87 & $\pm 29,70$ & 23 & 3 & 47,58 & $\pm 28,06$ & 18 & 43,26 & $\pm 24,47$ \\
\hline & & Máx. & 27 & 68,75 & $\pm 26,30$ & 25 & 64,82 & $\pm 24,63$ & 18 & 8 & 58,25 & $\pm 19,94$ & 20 & 58,30 & $\pm 24,10$ \\
\hline & & Total & 55 & 60,09 & $\pm 26,90$ & 52 & 57,06 & $\pm 28,14$ & 41 & 1 & 52,26 & $\pm 25,11$ & 38 & 51,17 & $\pm 25,13$ \\
\hline & \multirow[t]{3}{*}{ Total } & pad & 56 & 67,94 & $\pm 30,69$ & 54 & 64,29 & $\pm 35,62$ & 46 & 6 & 64,29 & $\pm 31,20$ & 37 & 58,68 & $\pm 31,81$ \\
\hline & & Max. & 54 & 100,62 & $\pm 43,01$ & 50 & 90,96 & $\pm 37,38$ & 36 & 66 & 82,75 & $\pm 31,65$ & 40 & 98,51 & $\pm 55,63$ \\
\hline & & Total & 11 & 83,98 & $\pm 40,55$ & 10 & 77,11 & $\pm 38,69$ & 82 & 2 & 72,39 & $\pm 32,53$ & 77 & 79,37 & $\pm 49,68$ \\
\hline
\end{tabular}

Tabela 2: Resultados do teste ANOVA $(p<0,05)$ entre as situações meio, fase e velocidade, dos seguintes músculos: supra abdominal, infra abdominal, obliquo externo e reto femoral.

\begin{tabular}{ccccccccc}
\hline Situação & \multicolumn{2}{c}{ Supra abdominal } & \multicolumn{2}{c}{ Infra abdominal } & \multicolumn{2}{c}{ Reto femoral } & \multicolumn{2}{c}{ OblíquoExterno } \\
\hline & $\mathrm{F}$ & $\mathrm{p}$ & $\mathrm{F}$ & $\mathrm{P}$ & $\mathrm{F}$ & Sig & $\mathrm{P}$ & Sig \\
Meio & 18,76 & 0,000 & 14,530 & 0,000 & 52,829 & 0,000 & 39,011 & 0,000 \\
Fase & 108,41 & 0,000 & 60,384 & 0,000 & 84,603 & 0,000 & 104,608 & 0,000 \\
Velocidade (Vel.) & 44,89 & 0,000 & 21,642 & 0,000 & 45,548 & 0,000 & 12,745 & 0,001 \\
Meio *Fase & 2,04 & 0,156 & 7,104 & 0,009 & 6,158 & 0,016 & 6,705 & 0,012 \\
Meio*Vel. & 12,41 & 0,001 & 9,258 & 0,003 & 1,432 & 0,236 & 10,428 & 0,002 \\
Fase*Vel. & 12,31 & 0,001 & 6,459 & 0,013 & 18,425 & 0,000 & 5,613 & 0,020 \\
Meio*Fase*Vel. & 0,29 & 0,588 & 0,089 & 0,766 & 0,947 & 0,334 & 0,005 & 0,947 \\
\hline
\end{tabular}


Na tabela 2 estão descritos os resultados da análise de variância para cada músculo analisado pelas variáveis fase, velocidade e meio. Na análise dos resultados das tabelas 1 e 2 observa-se que: $\mathrm{O}$ efeito principal meio indica que o percentual de ativação do sinal eletromiográfico difere nos dois ambientes para todos os músculos. O efeito principal fase indica que existem diferenças entre as duas fases do movimento independente do meio e da velocidade. O efeito principal velocidade indica que existem diferenças significativas em realizar os exercícios na velocidade padrão e na velocidade máxima.

$\mathrm{O}$ efeito da interação meio com fase indica que a fase do movimento interage com o meio em que o exercício é realizado, ou seja, o decréscimo da atividade EMG entre os dois valores médios da fase ascendente e descendente na água e a diferença entre os dois valores médios da fase ascendente e descendente em terra demonstraram valores estatisticamente diferentes, ou seja, a fase interfere de forma e intensidade diferentes, dependendo do meio e da musculatura. Apenas no músculo supra abdominal não existiram diferenças; o efeito fase interfere da mesma forma, ou com a mesma intensidade, tanto na água quanto na terra.

Para os outros músculos, a interação da fase com o meio apresentou comportamentos estatisticamente diferentes. Isto significa que o efeito da interação do meio com velocidade indica que existem diferenças estatisticamente significativas nos resultados referentes à percentagem de ativação do sinal eletromiográfico na maioria dos músculos, com exceção do músculo reto femoral. Interagindo a velocidade com o meio, observa-se que a diferença entre os dois valores médios da velocidade máxima com a velocidade padrão no supra abdominal, no infra-abdominal e no oblíquo externo, é maior, no meio líquido, que a diferença entre os dois valores em terra, indicando assim que há uma maior influência da velocidade no meio líquido quando relacionado com a terra. Já para o músculo reto femoral, o decréscimo da atividade EMG da velocidade máxima para a velocidade padrão, tanto no meio líquido como no terrestre, demonstrou-se estatisticamente igual. A velocidade máxima de execução, bem como a velocidade padrão, apresentam percentuais de ativação estatisticamente diferentes quando o exercício é realizado na água.
O efeito da interação da fase com a velocidade indica que existem diferenças estatisticamente significativas nos resultados referentes à atividade eletromiográfica dos músculos. Isto quer dizer que a diferença da atividade EMG entre os valores médios da velocidade máxima e padrão, na fase ascendente, apresentam maiores variações que na fase descendente. A atividade EMG nos quatro músculos apresenta uma maior influência do efeito velocidade na fase ascendente em relação à descendente.

$\mathrm{Na}$ interação entre o meio terrestre e aquático nas fases ascendente e descendente, durante a execução do exercício na velocidade padrão e máxima dos músculos supra abdominal, infra-abdominal, oblíquo externo e reto femoral, não foram encontradas diferenças estatisticamente significantivas. Isto significa que a diferença entre os valores médios da velocidade máxima e da velocidade padrão, da fase ascendente, menos a diferença entre os valores médios da velocidade máxima e da velocidade padrão, da fase descendente, no meio líquido, são iguais quando se compara com a diferença entre os valores médios da velocidade máxima e da velocidade padrão, da fase ascendente, menos a diferença entre os valores médios da velocidade máxima e da velocidade padrão, da fase descendente, em terra.

Demonstrando que a atividade EMG se apresentou semelhante para os quatro músculos, quando se fez a interação entre a fase, a velocidade e o meio. 

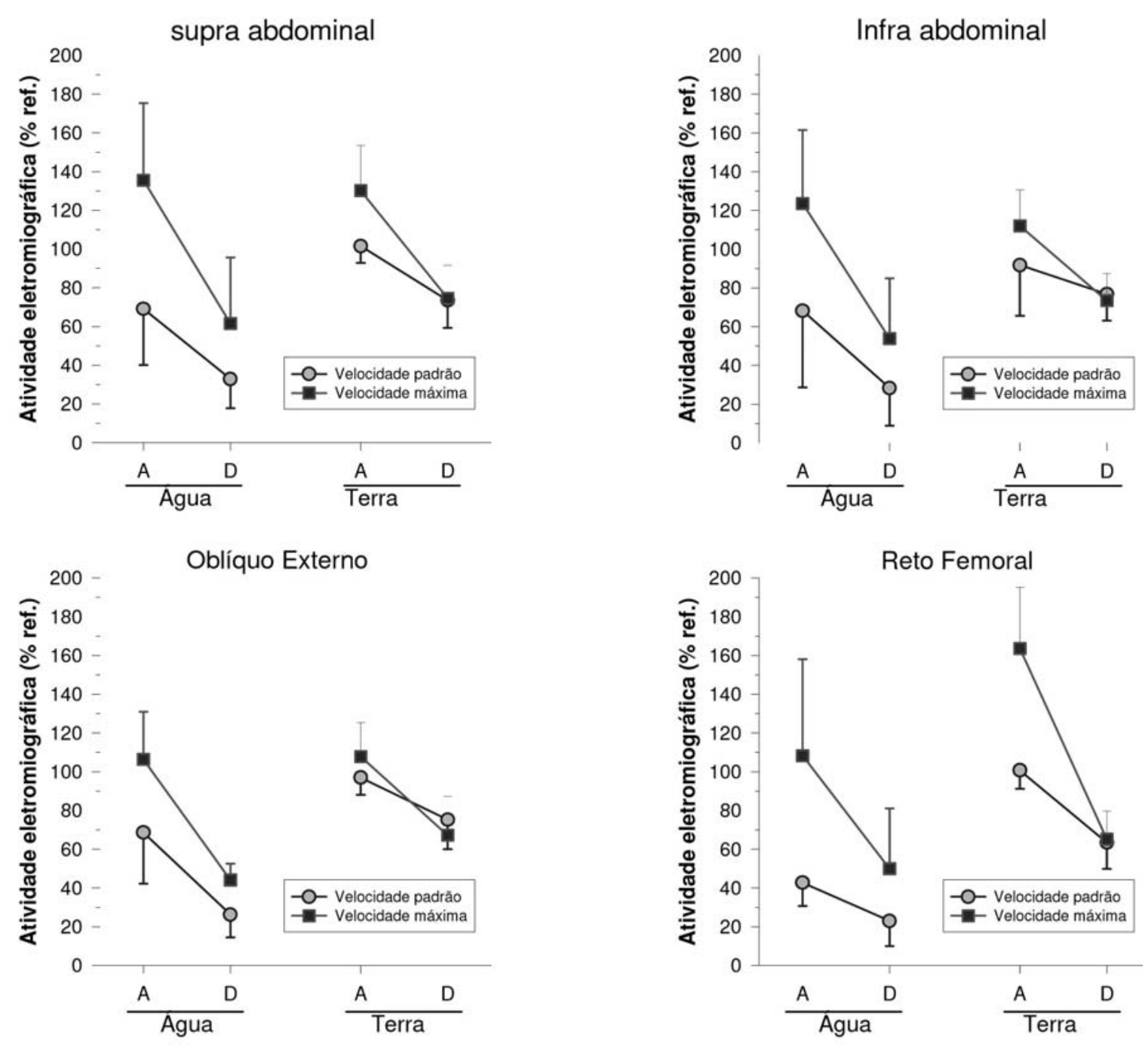

Figura 1: Representação gráfica da interação entre o meio líquido e terrestre, na velocidade máxima e na velocidade padrão nas fases ascendente $(A)$ e na fase descendente $(D)$, de cada músculo analisado.

\section{DISCUSSÃO}

O objetivo deste trabalho foi avaliar as respostas dos sinais eletromiográficos do exercício abdominal realizado dentro e fora da água. Analisando o fator principal velocidade, pode-se observar que, independente da fase e do meio em que o exercício foi realizado, a velocidade máxima apresentou valores superiores aos da velocidade padrão. Isto vem de encontro aos dados de Masuda et al. (20), que ao avaliarem a influência da força e da velocidade na resposta do sinal eletromiográfico, em exercícios dinâmicos realizados em terra, demonstraram em seus resultados que a amplitude do sinal eletromiográfico aumenta com o aumento da velocidade de execução dos exercícios. Além disto, outros autores (2) sugerem que o sistema nervoso central possui mecanismos que per- 
mitem ativar, de modo seletivo, unidades motoras que inervam as fibras IIb, sem que seja necessário ativar primeiro as fibras lentas, durante a execução de movimentos realizados em velocidades máximas. Isto ocasiona um aumento na atividade eletromiográfica dos músculos que intervêm no movimento e que são analisados, pois, segundo os mesmos autores, uma maior ativação se dá devido ao aumento da velocidade de execução, que ocasiona um aumento na freqüência de impulso nervoso das unidades motoras que inervam as fibras musculares rápidas. Ao analisar-se a diferença entre os valores do sinal eletromiográfico nas duas velocidades, levando-se em consideração o meio de execução, observa-se que ocorreram maiores variações no meio líquido. A diferença entre a velocidade máxima e a velocidade padrão no meio líquido foi maior que a da terra. Essa diferença sugere que a atividade eletromiográfica no exercício realizado no meio líquido sofre maiores variações quando ocorre mudança de velocidade. Isto pode ser explicado pela equação dos fluidos:

$$
\mathrm{Fd}=0,5 . \rho . A . V^{2} . \mathrm{Cd} \text {. }
$$

onde $\rho$ é a densidade do fluído, A é a área de superfície projetada, $\mathrm{V}$ é a velocidade do movimento e $\mathrm{Cd}$ é o coeficiente de arrasto (26).

Pöyhönen et al. (24) sugerem que a força de arrasto é definida como a força de resistência ao movimento, com sentido contrário ao mesmo. A relação entre a força exercida no meio líquido e a velocidade do movimento não é linear, ou seja, a força aumenta com o quadrado da velocidade de acordo com a equação descrita acima. Assim os autores indicam que a velocidade de execução no meio líquido apresenta uma maior atividade eletromiográfica, quando comparada com a execução em terra. Os autores confirmam que as forças que atuam sobre a musculatura dentro da água, quando se realiza um movimento, são a força de arrasto e o empuxo.

$\mathrm{Na}$ análise do fator fase, independente do meio de execução e da velocidade do movimento, a fase ascendente apresentou valores maiores que os da fase descendente. Essa menor atividade EMG no meio terrestre, na fase descendente, dos músculos ativados possivelmente se dá devido à atuação dos componentes elásticos do músculo, que auxiliam na frenagem do movimento, diminuindo a resposta da atividade EMG dos músculos abdominais. O que é corroborado pelos achados de Komi (15), assim como de Linnamo et al. (18), que obtiveram um sinal EMG maior nas fases concêntricas, quando relacionado com o das fases excêntricas, durante os exercícios por eles analisados. No meio líquido existe uma atividade excêntrica da musculatura, principalmente em movimentos rápidos, com a intenção de frear o movimento e iniciar o processo de mudança de direção do mesmo (26).

Estes estudos foram realizados somente em terra, porém, estão de acordo com os resultados desta pesquisa, onde os valores das fases concêntricas também foram superiores aos valores obtidos durante as fases excêntricas. Andersson et al (1) relatam que, ao analisarem diferentes exercícios de treinamento para a musculatura abdominal e flexora do quadril, encontraram em seus resultados uma atividade do sinal EMG dos músculos analisados maior, durante a fase ascendente em relação à fase descendente. Konrad et al. (17) também relatam que, ao analisarem a resposta da atividade elétrica da musculatura abdominal, durante a execução de alguns exercícios específicos para esta musculatura, observaram em seus resultados que durante a fase ascendente do movimento do tronco, na ação concêntrica, os resultados indicaram uma média de ativação EMG de $50 \%$ da contração voluntária máxima (CVM), enquanto que na fase descendente, na ação excêntrica, os resultados indicaram uma média de $35 \%$ da contração voluntária máxima.

No meio líquido, a resposta da atividade elétrica muscular na fase descendente indicou valores inferiores aos da descendente, em terra. Esta diferença entre as fases, neste estudo, acontece provavelmente devido à característica da atividade muscular.

Corroborando com esses achados e com esta suposição, Figueiredo (8), analisando as respostas do sinal EMG em diferentes exercícios abdominais no meio líquido, obteve em seus resultados uma atividade EMG menor durante a contração excêntrica, em relação à fase de contração concêntrica. Segundo o autor, durante a fase descendente do exercício em terra, encontra-se uma ação da musculatura dos flexores da coluna com uma contração excêntrica, trabalhando contra uma resistência unidirecional, ocasionada 
pela ação da gravidade, a qual proporciona à musculatura abdominal um trabalho de frenagem.

Enquanto que durante a fase descendente na água a resistência é multidirecional e a força vertical oposta à gravidade faz com que haja a necessidade de uma ação agonista da musculatura extensora da coluna vertebral (apesar de não monitorada - o autor referese a uma possível atividade) o que justifica o motivo pelo qual, no meio líquido, encontrou-se, em todos os músculos analisados, resultados na atividade EMG na fase descendente sempre menores que a resposta da atividade EMG na fase ascendente. Os resultados desta investigação corroboram os estudos de Figueiredo (8), de Pöyhönen et al. (23, 26) e de Costill et al. (4). Para estes autores, a contração utilizada, predominantemente, no meio líquido é a concêntrica, pois a musculatura age sempre contra uma resistência, devido, segundo os autores acima citados, ao fluxo turbulento e irregular dos movimentos repetidos, o que aumenta a resistência e modifica a função neuromuscular. Além disso, a justificativa do sinal EMG encontrado na água na fase excêntrica, segundo Pöyhönen et al. (24), ao estudarem a musculatura flexora extensora do joelho dentro e fora da água, deve-se ao fato de que a mudança de agonista para antagonista se dá pela repetição do movimento. Esta cria um padrão de fluxo diferente da água em cada subida e descida, provocando a necessidade de uma desaceleração do movimento da perna antes do final do movimento, a qual ocasiona uma pré-ativação que precede a mudança de direção do movimento, assim como neste estudo.

Em relação ao fator meio em que o exercício foi realizado, independente da fase e da velocidade de execução do mesmo, os valores do percentual de ativação do sinal eletromiográfico foram superiores na terra, quando comparados com os percentuais obtidos em água. Esta diferença encontrada na resposta da atividade eletromiográfica entre o meio líquido e o terrestre, neste estudo, corrobora os resultados de Pöyhönen et al. (25). Segundo o autor, essa diferença do sinal eletromiográfico entre os dois meios pode ser explicada pela redução do peso hidrostático dos indivíduos, quando imersos no meio líquido. Para os autores, esta diminuição do peso (força que atrai a massa de um corpo para baixo resultante da ação da gravidade) sofre a ação no meio líquido de outra força conhecida como empuxo, que é uma força vertical, de baixo para cima, exercida pelo líquido sobre o corpo nele imerso, sendo então esta força responsável pela diminuição do sinal EMG na água. Segundo os autores, o peso hidrostático afetaria o sistema neuromuscular, principalmente o fuso muscular e os proprioceptores que atuam durante as contrações voluntárias. A atividade dessas duas estruturas, o fuso muscular e os proprioceptores, estaria diminuída no meio líquido. Segundo Nigg e Herzog (22), os músculos esqueléticos contraem em resposta ao estímulo eletroquímico. Células nervosas especializadas chamadas neurônios motores propagam os potenciais de ação às fibras musculares. A necessidade de um menor número de unidades motoras recrutadas para o movimento executado na água, em relação ao mesmo movimento executado em terra, fica esclarecida devido à diminuição do peso hidrostático do indivíduo imerso na água, consequentemente demonstrando um sinal EMG reduzido, quando se compara com o sinal EMG obtido em terra. Corroborando esses achados, Sugajima et al. (30), estudando as mudanças da atividade das unidades motoras durante uma contração isométrica dos flexores do quadril no meio líquido, observaram que esta diminuição parcial do peso corporal do indivíduo imerso na água até os ombros mudou as características do recrutamento das unidades motoras. No meio terrestre os exercícios abdominais mais convencionais são realizados através da flexão do tronco, elevação das pernas e combinação de dois destes movimentos. O posicionamento destes segmentos irá modificar a resistência oferecida ao movimento, através de um aumento ou diminuição do braço de resistência. O exercício abdominal sit up, realizado neste estudo no meio líquido, apoiou os membros superiores no aquatubo, o qual aumenta o efeito da flutuação e mantém a cabeça do indivíduo fora da água. Como durante o exercício se manteve a posição horizontalizada dos membros inferiores, deve ocorrer atividade muscular para anular a tendência de rotação. $O$ fato de a pelve não estar no chão modifica bastante a característica do movimento, pois, nesta circunstância, o corpo tende a rodar ainda mais, à medida que a cabeça se eleva. Nesta investigação denota-se que a tendência de rolamento 
lateral é limitada, no exercício abdominal aquático realizado neste estudo, pelo tubo e pelo efeito de flutuação sobre ele, que servem como auxiliares da estabilização que sustenta os membros superiores. Nesse caso, o desequilíbrio e a tendência seriam de as pernas descerem e não rodarem. Devido à superfície instável, esperava-se uma maior interferência do músculo oblíquo externo, como foi encontrado no estudo de Garcia et al. (12). Estes investigadores mostram a influência da instabilidade da superfície na atividade eletromiográfica ao analisarem a flexão de tronco em cima de uma superfície estável, sobre um apoio de fisioterapia instável e em duas posições sobre uma bola com tendência de rolamento lateral. Apesar de a atividade do músculo reto abdominal quase dobrar no exercício realizado sobre a bola, a do oblíquo externo aumentou, aproximadamente, quatro vezes. Figueiredo (8), comparando a atividade EMG dos músculos abdominais no meio líquido, durante a execução do exercício sit up sem e com apoio nos membros inferiores, observou que durante o exercício sem apoio houve uma grande ativação para a estabilização dos membros inferiores. Neste exercício o executante mantém a posição pélvica com as pernas na horizontal, enquanto realiza a flexão do tronco tendo o eixo de movimento nas vértebras. Nesta situação ocorre um grande braço de resistência em relação ao eixo e, à medida que a cabeça se desloca para frente na flexão do tronco, a tendência de rotação aumenta.

Ao analisarmos o movimento de flexão do tronco no meio líquido verificamos que ocorre uma modificação no eixo de movimento. À medida que ocorre a flexão, ela passa do tronco para o quadril e o eixo de movimento se desloca para baixo, junto com a flexão do joelho. Ocorre uma diminuição do braço de resistência e um menor apoio para exercer desta forma a força. Este fator de modificação do eixo de movimento pode ter influenciado, neste estudo, uma menor atividade EMG durante o exercício realizado no meio aquático na velocidade padrão. Ekholm et al. (6), estudando as flexões de tronco, sugeriram que o fato de estar com os pés presos permitiria um momento de resistência que, provavelmente, aumentaria a ativação. Se o exercício em terra tem o apoio rígido do chão, o mesmo não ocorre com o exercício no meio líquido, pois, ao exercer força, a água cede, ocorrendo deslocamento do eixo do movimento. O exercício aquático acontece com o apoio do aquatubo nos membros superiores, estando a pelve e o quadril sem um ponto de apoio, ocorrendo, assim, o deslocamento do eixo de movimento. Dessa forma, o músculo reto femoral teria a sua capacidade de exercer força na flexão do quadril prejudicada no exercício aquático.

Um segundo fator importante, além da modificação do eixo de movimento, é o tipo de superfície de apoio. Em um estudo analisando diferentes superfícies de apoio, Garcia et al. (12) encontraram um aumento da amplitude eletromiográfica na musculatura abdominal, quando o exercício de flexão do tronco é realizado sobre uma superfície instável. Nessa situação, ocorre simultaneamente necessidade de contração para realizar o movimento e para estabilizar o tronco e todo o corpo. Dessa forma, a opção por posturas que gerem a maior instabilidade possível pode ser uma estratégia para uma grande ativação muscular nos exercícios abdominais realizados na água. O reto femoral, neste estudo, demonstrou um comportamento diferente em relação aos outros músculos estudados. Em terra observa-se uma grande atividade do reto femoral no exercício com apoio. Este fato pode estar relacionado à combinação do movimento rápido e à fixação dos pés. Guimarães et al. (13) e Andersson et al. (1) concluíram que os sit up realizados com os pés presos aumentam a atividade do músculo reto femoral, independentemente de os joelhos estarem estendidos ou flexionados. É importante observar que a fixação do pé ao chão proporciona uma melhor mecânica para o músculo reto femoral exercer força, possivelmente pela fixação do eixo de movimento. Além do apoio dos pés, os exercícios em seco, tanto na velocidade máxima como na padrão, têm o apoio da pelve no chão, o que estabiliza o eixo de movimento, facilitando a ação da musculatura reto femoral. Na água observamos uma redução da ativação do reto femoral, o que indica que o exercício sit up na água ameniza as ações dos flexores do quadril. Devido, provavelmente, à diminuição do peso hidrostático, onde um menor número de unidades motoras é necessário para a contração isométrica do reto femoral durante a estabilidade do quadril para a execução do exercício abdominal, um outro fator influente deve ser o não apoio e a não fixação dos pés. 
Observa-se então que a velocidade máxima no exercício realizado na água parece não ser o principal fator de influência na ativação do reto femoral. Hildenbrand e Noble (14) relatam que o reto femoral em exercícios abdominais se torna mais ativo quando o corpo está numa base instável. Com isso o reto femoral auxiliaria na estabilização do tronco. Mas esses achados não corroboram os resultados desta investigação, porque os sinais captados do músculo reto femoral EMG na água indicaram valores bem mais inferiores do que em terra, tanto na velocidade máxima, como na velocidade padrão. Analisando, então, as respostas descritas e observadas neste estudo, um dos principais interventores da atividade EMG dos músculos aqui analisados, no meio líquido, é a velocidade, pois, quando o exercício é realizado na velocidade padrão, a influência do peso hidrostático do indivíduo imerso é maior. Este efeito do peso hidrostático é citado por Pöyhönen et al. (25) como uma possível causa de uma menor ativação muscular na extensão do joelho no meio líquido. Enquanto que o exercício, quando realizado na velocidade máxima, apresentou uma grande atividade eletromiográfica, isto, provavelmente, pelo fato de a resistência no meio líquido ser proporcional ao quadrado da velocidade do objeto que está se deslocando, proporcionando, assim, uma sobrecarga bastante grande dos músculos abdominais no meio líquido, com exceção do músculo reto femoral que foi menor. Dessa forma, a realização dos exercícios na máxima velocidade parece ser uma excelente ferramenta para atingir elevados níveis de ativação muscular nos exercícios realizados no meio líquido. Indicando também que a instabilidade da posição horizontalizada e a resistência ao movimento compensam a diminuição do peso hidrostático quando o exercício é executado na velocidade máxima. Ou seja, nesta investigação, durante o exercício na água na velocidade padrão, deve haver uma ativação muscular ocasionada pela dificuldade de estabilização e controle de postura, mas estes não chegam a ser suficientes para compensar a diminuição do peso hidrostático, enquanto que o aumento da resistência proporcionado pela velocidade máxima no meio líquido é suficiente para aumentar a atividade EMG dos músculos supra, infra e oblíquo externo, compensando a diminuição do peso hidrostático. Sendo a velocidade máxima no exercício realizada na água, parece não ser o principal fator de influência na ativação do reto femoral.

\section{CONCLUSÕES}

O comportamento da atividade eletromiográfica na execução de exercícios abdominais demonstrou que realizá-los em velocidade máxima, tanto em terra quanto em água, apresentou grande resposta na ativação dos músculos analisados, principalmente na fase ascendente. As diferenças no sinal eletromiográfico entre as velocidades padrão e máxima são maiores no exercício feito na água, quando comparado com o realizado em terra. Percebe-se, assim, que o uso da variação da velocidade é um recurso em exercícios ministrados em água. Maiores velocidades proporcionam maior resistência ao movimento e consequentemente maior atividade muscular. Ao executar um exercício abdominal no meio líquido, realmente enfatiza-se a ação da musculatura abdominal, já que esta apresenta maior atividade na fase ascendente e com pequena atividade muscular do flexor do quadril.

\section{CORRESPONDÊNCIA}

Evelyn Souto Martins Müller

Rua Coronel Bordini, 1180, ap: 22

Bairro Auxiliadora

90440-003 Porto Alegre, RS.

Brasil

evelynmueller@terra.com.br 


\section{REFERÊNCIAS}

1. Andersson EA, Nilsson J, Zhijia MA, Thorstensson A (1997). Abdominal and hip flexor muscle activation during various training exercise. Eur J Appl Physiol 75: 115-123.

2. Badillo J, Ayestarán E (2001). Fundamentos do treinamento de força. 2.ed. Porto Alegre: Manole

3. Clarys JP (1985). Hydrodynamics and electromyography: ergonomics aspects in aquatics. Appl Ergon Sport 16: 11-24

4. Costill DL, Maglischo EW, Richardson AB (1992). Handbook of Sports Medicine and Science Swimming. Oxford: Blackwell Scientific Publications

5. Ervilha UF, Duarte M, Amadio AC (2001). Padrão do sinal Eletromiográfico de músculos do membro inferior e Cinemática do joelho durante o andar em ambiente aquático e terrestre. Anais do IX Congresso Brasileiro de Biomecânica, vol. 2, 290-294

6. Ekholm J, Arborelius U, Fahlcrantz A, Larsson A, Mattsson G (1979). Activation of abdominal muscles during some physiotherapeutic exercises. Scand J Rehab Med 11: 75-84

7. Figueiredo PAP, Borges Jr NG, Tartaruga LAP, Kruel LFM (2003). Metodologia para o isolamento do sistema de coleta eletromiografica em meio líquido. Apresentação no Congresso Brasileiro de Esportes, Fitness e Ciências da Saúde.

8. Figueiredo PAP (2004). Análise Eletromiográfica de Exercícios Abdominais Realizados por Mulheres no Meio Líquido. Dissertação de Mestrado em Educação Física. Universidade Federal do Rio Grande do Sul

9. Frangolias DD, Rhodes EC (1996). Metabolic Responses and Mechanisms During Water Immersion Running and Exercise. Sports Med 22: 38-53

10. Frangolias DD, Rhodes EC, Taunton JE (1996). The effect of familiarity with deep water running on maximal oxygen consumption. J Strength Condit Res 10: 215-219

11. Fujisawa H, Suenaga N, Minami A (1998). Electromyographic study during isometric exercise of the shoulder in head-out water immersion. J Shoulder Elbow Surg 7: 491-494

12. Garcia V, Grenier SG, McGill SM (2000). Abdominal muscle response during curl-ups on stable and labile surfaces. Phys Ther 80: 564-569

13. Guimarães ACS, Vaz MA, Campos MIA, Marantes R (1991). The contribution of the rectus abdominis and retus RForis in twelve selected abdominal exercises. $J$ Sports Med Phys Fitness 31: 222-230

14. Hildenbrand K, Noble L (2004). Abdominal muscle activity while performing trunk-flexion exercises using the $\mathrm{Ab}$ Roller, ABslide, FitBall, and conventionally performed trunk curls. I Athl Train 39: 37-43

15. Komi PV (2000). Stretch-shortening cycle: a powerful model to study normal and fatigued muscle. J Biomech 33: 1197-1206

16. Komi PV, Linnamo V, Silventoinen P, Sillanpää M (2000). Force and EMG power spectrum during eccentric and concentric actions. Med Sci Sports Exerc 32: 1757-1762

17. Konrad P, Schmitz K, Denner A (2001). Neuromuscular evaluation of trunk-training exercises. J Atlhl Train 36: 109-118

18. Linnamo A, Moritani T, Nicole C, Komi PV (2003). Motor unit activation patterns during isometric, concentric and eccentric actions at different force levels. J Electromyogr Kinesiol 13: 93-101
19. Masumoto K, Takasugi SI, Hotta N, Fujishima K, Iwamoto Y (2004). Electromyographic analysis of walking in water in healthy humans. J Physiol Anthropol Appl Human 23: 119-127

20. Masuda T, Kizuka T, Yong ZJ, Yamada H, Saitou K, Sadoyama T, Okada M (2001). Influence of contraction force and speed on muscle fiber conduction velocity during dynamic voluntary exercise. J Electromyogr Kinesiol 11: 85-94

21. Madureira AS, Lima SMT (1998). Influência do treinamento físico no meio aquático para mulheres na terceira idade. Rev Brasil Ativ Fís Saúde 3 (3): 59-66

22. Nigg BM, Herzog W (Eds) (1998). Biomechanics of the musculo-skeletal system. 2. ed. London: John Wiley \& Sons

23. Pöyhönen $\mathrm{T}$, Kyrolainen $\mathrm{H}$, Keskinen KL, Hautala A, Savolainen J, Malkia E (2001). Electromyographic and kinematic analysis of therapeutic knee exercises under water. Clin. Biomech 16: 496-504

24. Pöyhönen T, Keskinen KL, Kyrolainen H, Hautala A, Savolainen J, Malkia E (2001). Neuromuscular function during therapeutic knee exercise under water and on dry land. Arch Phys Med Rehabil 82(10): 1446-52

25. Pöyhönen T, Keskinen K, Savolainen J, Hautala A, Esko M (1999). Human isometric force production and electromyogram activity of knee extensor muscles in water and on dry land. Eur J Appl Physiol 80: 52-56

26. Pöyhönen T, Sipila S, Keskinen KL, Hautala A, Savolainen J, Malkia E (2002). Effects of aquatic resistance training on neuromuscular performance in healthy women. Med Sci Sports Exerc 34: 2103-2109

27. Prilutsky BI, Gregor RJ, Ryan MM (1998). Coordination of two-joint rectus femoris and hamstrings during the swing phase of human walking and running. Exp Brain Res 120: 479-486

28. Ruoti RG, Troup JT, Berger RA (1994). The effects of nonswimming water exercise on older adults. J Orthop Sports Phys Ther 19: 140-145

29. Skinner AT, Thomson AM (1985). Exercícios na água. São Paulo: Manole

30. Sugajima Y, Mitarai G, Koeda M, Moritani T (1996). Characteristic changes of motor unit activity in hip joint flexor muscles during voluntary isometric contraction during water immersion. J Electromyogr Kinesiol 6: 83-95

31. Takeshima N, Rogers E, Watanabe WF, Brechue ATM, Islam, Hayano J (2002). Water-based exercise improves health-related aspects of fitness in older women. Med Sci Sports Exerc 33: 544-551

32. Taunton JE, Rhodes EC, Wolski LA, Donelly M, Warren J, Elliot J, McFarlane L, Leslie J, Mitchel J, Lauridsen B (1996). Effect of land-based and water-based fitness programs on the cardiovascular fitness, strength and flexibility of women aged 65-75 years. Gerontology 42: 204-210

33. Vaz MA, Bertcht V, Trombini RS, Costa MS, Guimarães ACS (1997). Comparação da atividade elétrica do músculo reto abdominal e oblíquo externo em exerc' cios abdominais com e sem utilização de aparelhos. Anais Congresso Brasileiro de Biomecânica, vol 7: 441-446

34. Wilder RP, Brennan DK (1993). Physiological responses to deep water running in athletes. Sports Med 16: 374-380 